\title{
Effect of Glutathione on Lipogenesis in Liver Slices from Rats Fed on Low Casein Diet
}

\author{
Katuhiko NoDA \\ Department of Nutrition, School of Medicine, Tokushima University \\ Received August 31, 1972
}

\begin{abstract}
To study the mechanism of fatty infiltration in the liver due to added sulfur-containing amino acids to low casein diet, the effect of sulfur-containing amino acids and glutathione (GSH) on the incorporation of acetate-1 $1{ }^{14} \mathrm{C}$ into lipid fractions were studied in liver slices from rats fed on $8 \%$ casein diet (Basal diet) with or without added methionine (Met).

The liver acetyl Co A carboxylase activities of rats on basal diet with or without added Met were similar.

Addition of Met, cystine or cysteine to the incubation medium had little effect on lipogenesis of slices. On addition of GSH to liver slices from rats fed on basal diet, lipid formation increased appreciably. On the other hand, addition of GSH to liver slices from rats fed on Met supplemented diet showed no accelerative effect on lipogenesis.

Addition of GSH to the incubation medium of liver slices from rats fed on basal diet tended to reduce the incorporation of acetate into the phospholipid fraction and to increase into the fatty acid fraction of liver slices.

The content of liver GSH was lower in rats on basal diet than in those on Met supplemented diet. The higher GSH level in rats on Met supplemented diet may be one factor causing fatty infiltration in the liver of these animals.
\end{abstract}

The liver of rats fed a diet containing $8 \%$ casein (Basal diet) have a normal lipid content, but addition of $0.3 \%$ Met (Met diet) to basal diet induces a fatty liver. ${ }^{11}$ There have been several reports on this subject from our laboratory $^{2 \sim 4}$ and elsewhere. ${ }^{5 \sim 7 /}$ It has been suggested that fatty infiltration of the liver on addition of Met to basal diet might be due to increased lipogenesis by increased insulin production resulting from an adequate supply of sulfur-containing amino acids in the diet.4) However, even if true, this does not seem to be the only reason, since in alloxan diabetic rats, the lipid content in the liver of rats on Met diet was slightly higher than that of animals on basal diet. ${ }^{4}$

Accordingly, to see if any factor(s) other than insulin was involved in lipid accumulation under these conditions, the effects of sulfur-containing amino acids and GSH on lipogenesis in liver slices were studied.

The abbreviation used in this paper include: GSH, glutathione; Met, methionine: GSSG, oxidized glutathione; CoA, coenzyme A.
The activity of acetyl Co A carboxylase (EC 6.4.1.2) was also examined since the enzyme is important in regulation of long-chain fatty acid synthesis. ${ }^{8)}$

\section{MATERIALS AND METHODS}

Animals and diets. Female Wistar strain rats, weighing $60 \sim 80 \mathrm{~g}$, were used. They were kept in individual wire-bottomed cages at $23 \pm 1^{\circ}$, and given laboratory chow (Formula MF, purchased from Oriental Yeast Co., Ltd., Tokyo, Japan) and water ad libitum for a few days before the feeding experiments. In experiment 1,15 rats were used. Five rats were killed at the beginning (day 0 ) of the feeding of experimental diets. The others were divided to 2 groups of 5 rats of equal total body weight. In experiment 2 , two groups of 5 rats each were used. One group was fed on basal diet and the other on basal diet supplemented with $0.3 \%$ Met (Met diet). Both groups were fed ad libitum. The composition of the diets were as follows: Laboratory chow: crude proteins, $25.3 \%$, crude fats 4.9 , water soluble non nitrogen compounds 51.5, and adequate vitamins and minerals. Basal diet: casein $8 \%$, corn oil 5 , sucrose 81 , balanced salt mixture 5 , balanced water-soluble vitamin mixture 0.85 , cholin- $\mathrm{Cl} 0.2$, and adequate amounts of fat-soluble 
vitamins (All components were purchased from Tanabe Amino Acid Research Foundation, Osaka, Japan). Met diet: Basal diet in which the sucrose was partially replaced by $0.3 \%$ Met.

Acetyl Co A carboxylase. One gram of the liver was homogenized with $3 \mathrm{ml}$ of $0.02 \mathrm{M}$ potassium phosphate buffer ( $\mathrm{pH} 7.0$ ) and the post mitochondrial supernatant was obtained by centrifugation. The activity of the liver acetyl Co A carboxylase was measured by the method of Waite and Wakil.9) Enzyme activity was measured from the decrease in optical density at $340 \mathrm{~nm}$ due to consumption of TPNH coupled with the fatty acid synthetase reaction using Hitachi Double Beam Spectrophotometer (Hitachi Industry Co., Ltd., Hitachi, Japan). Co A and TPNH were products of Sigma Chemical Co., Missouri, U.S.A. Acetic anhydride (Nakarai Chemical Co., Kyoto, Japan) was used for synthesis of actyl Co A. ${ }^{101}$

Assay procedures for lipogenesis. Rats were killed after 7 days by decapitation and their livers were removed and were chilled with ice. A slice was cut off from main lobe $(0.5 \mathrm{~mm}$ thick and about $100 \mathrm{mg}$ weight) and the remaining livers were stored at $-20^{\circ} \mathrm{C}$ for analysis of its lipid and GSH contents. In experiment 2, one gram of the liver was removed before storage for the assay of acetyl Co A carboxylase activity.

In experiments on lipogenesis in liver slices, the incubation medium was Krebs-Ringer phosphate buffer in experiment 1 , and Krebs-Ringer bicarbonate buffer in experiment 2 . In experiment $1, \mathrm{CO}_{2}$ was trapped in $0.4 \mathrm{ml}$ of $10 \% \mathrm{KOH}$ solution. Radioactivity in the trapped $\mathrm{CO}_{2}$ was counted in scintillation counter (Packard tri-carb liquid scintillation counter, Illinois, U.S.A.). The procedures for incubation and extraction of lipids were essentially as described by
Weiss et al. ${ }^{121}$ The incubation medium contained $2 \mu \mathrm{Ci}$ of sodium acetate- $1{ }^{14} \mathrm{C}$ (specific activity $49.5 \mathrm{mCi}$ / /mm, Daiichi Pure Chemical Co., Ltd., Tokyo, Japan). Slices were incubated for $2 \mathrm{hr}$ at $37^{\circ} \mathrm{C}$ with or without one of sulfur-containing amino acids (Kyowa Hakko Kogyo Co., Ltd., Tokyo, Japan) or GSH (Kojin Co., Ltd., Tokyo, Japan) at a final concentration of $1.0 \mathrm{~mm}$. Lipids were extracted with chloroform-methanol mixture. The solvent layer was evaporated off and then the extracted lipids were finally dissolved in $5.0 \mathrm{ml}$ of $n$-hexane. The hexane was washed several times with water and then $2.0 \mathrm{ml}$ were placed in a counting vial with $10 \mathrm{ml}$ of scintillation solution, ${ }^{13}$ and radioactivity was measured as described above.

The extracted lipids in hexane $(2.0 \mathrm{ml})$ were fractionated into phospholipids, cholesterol and fatty acids by the method of Bhattathiry. ${ }^{14\}}$ The radioactivity in each fraction was counted as above and was expressed as a percentage of the total radioactivity in all three lipid fractions.

Analysis. GSH in the livers was determined by the method of Jocelyn ${ }^{15}$ using concentrated hydrochloric acid. Total liver lipids were extracted from dried liver powder by a method fundamentally same as Soxhlet extraction and were measured gravimetrically.

Total protein in the liver was measured by a boric acid method of a micro-Kjeldahl. Determination of protein in the postmitochondrial supernatant used for the assay of acetyl Co A carboxylase activity was followed to the method of Lowry et al. ${ }^{16}$ :

\section{RESULTS}

\section{General observations}

The food intakes, weight gains and liver lipid contents of the experimental diets were shown in Table I. Those items of the group

Table I. Food Intake, Weight Gains and Liver Lipid Contents of Rats Fed ad libitum on Basal Diet with or without $0.3 \%$ Met For 7 Days

Compositions of experimental diets are shown in the text. Values cited are mean of 5 rats.

\begin{tabular}{cccc}
\hline Diet & $\begin{array}{c}\text { Food intake } \\
(\mathrm{g} / \text { day })\end{array}$ & $\begin{array}{c}\text { Weight gain } \\
(\mathrm{g} / \text { week })\end{array}$ & $\begin{array}{c}\text { Liver lipid } \\
(\% \text { dry weight })\end{array}$ \\
\hline Experiment 1 & & & \\
$\quad$ Laboratory chow & & & \\
Basal diet & - & - & $\left.8.6 \pm 0.7^{b}\right)$ \\
$\quad$ Met diet & 9.7 & 5.8 & $8.8 \pm 0.7$ \\
Experiment 2 & 10.9 & 20.0 & $20.3 \pm 1.4^{\circ}$ \\
Basal diet & & & \\
Met diet & 7.8 & 4.0 & $8.9 \pm 0.6$ \\
& 9.6 & 13.5 & $20.5 \pm 1.2^{\circ}$ \\
\hline
\end{tabular}

a) Day 0 of the feeding of experimental diet. b) Mean \pm SEM.

c) Difference from the respective values of the group on basal diet statistically significant at the $1 \%$ level. 
Table II. Effect of GSH and Sulfur-ContainING AMINo ACIDS ON LIPOGENESIS IN Liver Slices from Rats Fed Basal DIET ad libitum FOR 3 OR 7 DAYS

Liver slices were incubated with one of sulfurcontaining amino acids or GSH and the incorporation of acetate-1.14 $\mathrm{C}$ into lipid fractions was counted. Values are expressed as percentage of the respective control values observed on incubation without the test substances. The final concentration of the substances were $1.0 \mathrm{~mm}$

\begin{tabular}{crc}
\hline Substances & \multicolumn{2}{c}{ Feeding period (days) } \\
\cline { 2 - 3 } & \multicolumn{3}{c}{3} & 7 \\
\hline- & 100 & 100 \\
GSH & 152 & 207 \\
L-Met & 98 & 120 \\
L-Cysteine & 99 & 115 \\
L-Cystine & 99 & \\
\hline
\end{tabular}

fed on basal diet were less than those of the group fed on Met diet. For example, in experiment 1 , the weight gain of the basal diet group was less than one gram per day while that of the Met diet group $3 \mathrm{~g}$ per day. The liver lipid content of the former group remained at about $10 \%$, while that of the latter group increased to double within 7 days.

\section{Lipogenesis}

In preliminary test, liver slices from rats which had received basal diet were incubated with $1 \mathrm{~mm}$ GSH or sulfur-containing amino acids. Addition of GSH promoted the incorporation of acetate- $1-{ }^{14} \mathrm{C}$ into the lipid fractions especially in slices from rats fed for 7 days. The effect of the concentration of

Table III. Effect of GSH Added to the Incubation Medium on the Formation of CO2 and Lipids from Acetate-1. ${ }^{14} \mathrm{C}$ in Liver Slices from Rats Fed on Basal

Diet or Met Diet for 7 Days

The compositions of the diets are given in the text. Values cited are mean of 5 rats. Krebs-Ringer phosphate buffer was used and $\mathrm{CO}_{2}$ produced was trapped with $10 \% \mathrm{KOH}$ solution placed in a center well of a Warburg flask.

\begin{tabular}{|c|c|c|c|c|}
\hline \multirow[b]{2}{*}{ Diet } & \multirow{2}{*}{$\begin{array}{l}\text { Addition } \\
\text { of GSH }\end{array}$} & \multicolumn{2}{|c|}{ Products } & \multirow[b]{2}{*}{$\mathrm{B} / \mathrm{A}$} \\
\hline & & $\mathrm{CO}_{2}(\mathrm{~A})$ & Lipids (B) & \\
\hline \multicolumn{5}{|c|}{ (nmoles/mg protein per hour) } \\
\hline Laboratory chow & - & $5.27 \pm 0.28^{a !}$ & $1.01 \pm 0.05$ & 0.176 \\
\hline \multirow[t]{2}{*}{ Basal diet } & - & $3.40 \pm 0.36$ & $1.15 \pm 0.08$ & 0.337 \\
\hline & + & $4.05 \pm 0.40$ & $1.60 \pm 0.13^{b}$ & 0.387 \\
\hline \multirow[t]{2}{*}{ Met diet } & - & $3.92 \pm 0.35$ & $1.57 \pm 0.11^{b l}$ & 0.400 \\
\hline & + & $4.51 \pm 0.38$ & $1.48 \pm 0.10^{b}$ & 0.322 \\
\hline
\end{tabular}

a) Mean \pm SEM

b) Significantly different from basal diet group incubated without GSH $(p<0.01)$.

Table IV. Protein Contents, gSh levels and Acetyl Co A Carboxylase Activities in the Livers of Rats Fed on Basal Diet or Met Diet for 7 Days

\begin{tabular}{|c|c|c|c|c|c|}
\hline \multirow[b]{2}{*}{ Diet } & \multirow{2}{*}{$\begin{array}{c}\text { Total } \\
\text { protein }\end{array}$} & \multirow{2}{*}{$\begin{array}{l}\text { Total } \\
\text { GSH }\end{array}$} & \multirow{2}{*}{$\begin{array}{l}\text { Acetyl Co A } \\
\text { carboxylase }\end{array}$} & \multicolumn{2}{|c|}{ In vitro Lipogenesis } \\
\hline & & & & without GSH & with GSH \\
\hline & (mg/g liver) & ( $\mu \mathrm{g} / \mathrm{mg}$ protein) & $\begin{array}{l}\text { (-TPNH } \mu \text { moles/ } \\
\left.\text { mg protein }{ }^{a} / \mathrm{hr}\right)\end{array}$ & \multicolumn{2}{|c|}{ ( $\mu$ moles/mg protein per $\mathrm{hr}$ ) } \\
\hline Basal diet & $\begin{array}{l}179 \\
139\end{array}$ & $7.5 \pm 0.4^{6)}$ & $82.2 \pm 15.0$ & $2.60 \pm 0.10$ & $\begin{array}{l}4.00 \pm 0.36^{d \prime} \\
\left.3.40 \pm 0.32^{c}\right)\end{array}$ \\
\hline Met diet & 139 & $12.6 \pm 0.6^{\circ 1}$ & $104.4 \pm 23.4$ & & \\
\hline
\end{tabular}

a) Protein was measured in the postmitochondrial supernatant solution.

b) Mean \pm SEM for 5 rats.

c) Significantly different from the value of basal diet group $(p<0.05)$;

d) Significantly different from basal diet group incubated without GSH in the medium $(p<0.01)$. 


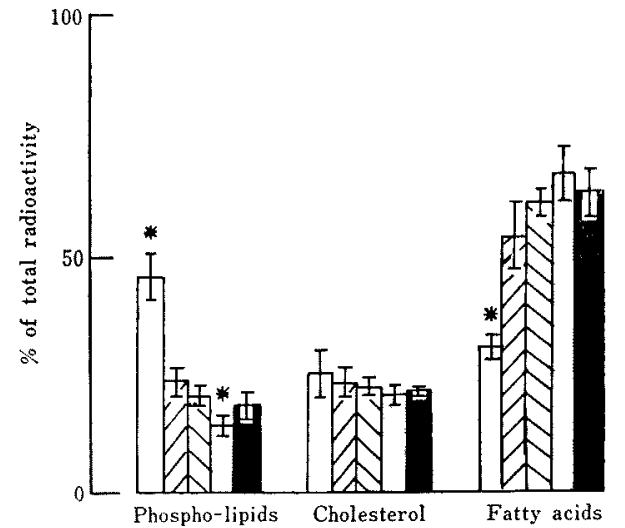

FIG. 1. Distribution of Acetate-1-14 C in Various Lipid Fractions of Liver Slices.

Rats were fed on laboratory chow, basal diet or Met diet for 7 days, and liver slices were incubated with or without GSH added in the incubation medium at a final concentration of $1.0 \mathrm{~mm}$. The absolute values of total lipid formed from acetate- $1-{ }^{14} \mathrm{C}$ are shown in Table III. Vertical bars denote standard errors.

Asterisk indicates value significantly different from the basal diet group incubated without $\mathrm{GSH}$ in the medium $(p<0.05)$.

$\square$, Laboratory chow; $\square$, Basal diet; $\triangle$, Basal diet + GSH; $\square$, Met diet; $\square$, Met diet + GSH.

GSH on the incorporation of acetate into lipids was examined. Concentration of 0.5 or $1 \mathrm{~mm}$ GSH caused increased lipogenesis, but with concentrations above $2.5 \mathrm{~mm}$, lipogenesis tended to decrease, being $90 \%$ of the control value with 5 or $10 \mathrm{~mm}$ GSH. GSSG caused as much stimulation as the GSH. Thus GSH increased lipogenesis and other sulfurcontaining amino acids tested did not show lipogenic effect in liver slices from rats fed on basal diet in which the most limiting amino acids were sulfur-containing amino acids. So the effect of GSH was tested on liver slices from rats fed on Met diet, in which sulfurcontaining amino acids was not the most limiting.

Effect of GSH on $\mathrm{CO}_{2}$ production and lipid formation from acetate- $1-{ }^{14} \mathrm{C}$ in slices from rats fed on basal diet was compared with those on Met diet. As shown in Table III, $\mathrm{CO}_{2}$ production increased slightly on addition of GSH to the incubation medium, although the increase was not statistically significant. Lipid formation in slices from rats fed on basal diet was markedly stimulated by GSH, while that in slices from animals fed on Met diet was not. Lipid formation in slices from basal diet group was elevated to that of slices from rats on Met diet by the supply of GSH to the medium. With the increase of lipogenesis by $\mathrm{GSH}$, the lipid $/ \mathrm{CO}_{2}$ ratio of basal diet group increased from 0.34 to 0.39 , the latter value was close to that of Met diet group.

\section{Acetyl Co $A$ carboxylase activity and GSH content}

In experiment 2 , the liver actyl Co A carboxylase activity and liver GSH content were measured. There was no significant difference in the enzyme activity in the livers of rats on basal diet and Met diet (Table IV). However, lipid formation in slices from rats on basal diet was stimulated more than $50 \%$ on addition of GSH, reaching to the level of slices. from rats on Met diet.

The livers of rats fed on Met diet contained more GSH than those of rats on basal diet, and the difference was statistically significant.

\section{Distribution of incorporated acetate- $1{ }^{14} \mathrm{C}$}

Analysis of the distributed acetate in various lipid fractions indicates the pattern of lipid synthesis. Results are shown in Fig. 1. In rats on laboratory chow the radioactivity was found more or less evenly distributed in three fractions; phospholipids, cholesterol and fatty acids. When rats were fed on basal diet or Met diet, acetate incorporation into the phospholipid fraction decreased. The rate of phospholipid synthesis was significantly higher $(p<0.05)$ in liver slices from rats on basal diet than that from rats on Met diet. The fatty acid fraction (mostly came from neutral fat fraction) tended to be more and the cholesterol fraction tended to be less in rats on Met diet than in rats on basal diet. On addition of GSH to the incubation medium the pattern in slices from rats on basal diet became slightly more like that of slices from rats on Met diet. 


\section{DISCUSSION}

Various effects of GSH in vitro have been reported. Ichihara et al. ${ }^{17}$ ) noticed the lipogenic effect of GSH on dispersed liver cells. $\mathrm{Chiba}^{18)}$ found that GSH and cysteine accelerated the passage of sugars into diaphragm and adipose tissue. Lavis and Williams ${ }^{19}$ reported that both GSH and cysteine activated lipogenesis in dispersed adipose tissue cells. In the present work, cysteine had a weak effect on lipogenesis in liver slices. While, GSH caused great stimulation. GSH effect in the medium may not be indirect, simply as a reducing agent, thus for instance increasing the supply of reduced adenine nucleotide, since both GSH and GSSG increased lipogenesis.

On adding Met to the basal diet, the stimulatory effect of GSH on lipogenesis in vitro was no longer observed. And the liver GSH content of the rats fed on Met diet increased. Sulfur-containing amino acids are the most limiting nutrient in basal diet. Thus the GSH level in the liver of the group fed on basal diet seems to restrict lipogenesis. By the rough calculation from GSH content in the livers measured, addition of approximately $1 \mathrm{~mm} \mathrm{GSH}$ to the incubation medium of liver slices from rats fed on basal diet may reach the resembled GSH concentration to the livers from rats fed on Met diet.

By feeding of experimental diets, fatty acid synthesis was induced with corresponding decrease of phospholipid and cholesterol synthesis. Fatty acid fraction, mostly came from triglycerides checked by autoradiography of thin layer chromatogram, was higher and phospholipid fraction was lower in Met diet group than in basal diet group. Ogura ${ }^{7}$ reported that fatty liver was induced by the increased triglyceride synthesis in the liver of rats fed on Met diet. In spite of the fact that the increased fatty acid synthesis in Met group, the activities of liver acetyl Co A carboxylase of rats on basal and Met diets were practically the same. According to Yoshida, no significant difference was ob- served in the fixation of ${ }^{14} \mathrm{CO}_{2}$ by acetyl $\mathrm{Co} \mathrm{A}$ to form malonyl $\mathrm{Co} \mathrm{A}$ in cell free system from rat livers on basal and Met diets (personal communication). The enzyme activity in the liver of rats fed on basal diet may be limited by the level of GSH. But the different rate of supply of substrate or reduced adenine nucleotide may be possible in vivo. Its possibility still remains to be elucidated.

GSH may act like insulin to increase $\mathrm{CO}_{2}$ production a little on its addition, but GSH stimulated lipid formation only in liver slices from rats fed on basal diet. On the other hand, addition of insulin in the medium augmented fatty acid synthesis in liver slices from rats fed on both basal and Met diets (unpublished data). Insulin and GSH seem to have different function on lipogenesis. These suggest that increase in the GSH level, together with increased insulin production, ${ }^{4)}$ due to added Met to basal diet may augment fatty acid synthesis in the liver, resulting in production of fatty liver.

\section{REFERENCES}

1) A. E. Harper, Am. J. Clin. Nutr., 6, 242 (1958).

2) A. Yoshida, K. Moritoki and K. Noda, Eiyo to Shokuryo, 19, 291 (1966).

3) K. Noda, ibid., 24, 89 (1971).

4) K. Noda, J. Nutr., 101, 1391 (1971).

5) A. Yoshida and A. E. Harper, J. Biol. Chem., 235, 2586 (1960).

6) M. Ogura H. Tanaka and A. Ito, Agr. Biol. Chem., 32, 920 (1968).

7) M. Ogura, ibid., 36, 1159 (1972).

8) S. Numa, W. M. Brotz and F. Lynen, Adv. Enzyme Regul., 3, 407 (1965).

9) M. Waite and S. J. Wakil, J. Biol. Chem., 237, 2750 (1962).

10) E. J. Simon and D. Shemin, J. Am. Chem. Soc., 75, 2520 (1953).

11) G. A. Bruno and J. E. Christion, Anal. Chem., 33, 1216 (1961).

12) J. F. Weiss, E. C. Naber and R. M. Johnson, J. Nutr., 93, 142 (1961).

13) H. Jeffay and J. Alvarez, Anal. Chem., 33, 612 (1961).

14) E. P. N. Bhattathiry, Brit. J. Nutr., 20, 553 (1966). 
15) P. C. Jocelyn, Anal. Biochem., 18, 493 (1967).

16) O. H. Lowry, N. J. Rosebrough, A. L. Farr and R. J. Randall, J. Biol. Chem., 193, 265 (1951).

17) A. Ichihara, K. Adachi, Y. Daikuhara and $Y$.
Takeda, J. Biochem. Japan, 57, 696 (1965).

18) T. Chiba, Yakugaku Zasshi, 89, 248 (1969).

19) V. R. Lavis and R. H. Williams, J. Biol. Chem., 245, 23 (1970). 